\title{
Necessity of Noise Map for Smart Protection from Environmental Noise
}

\author{
Yeoju Kim ${ }^{1,2}$, Woojae Han ${ }^{1,2,3}$ \\ ${ }^{1}$ Laboratory of Hearing and Technology, ${ }^{2}$ Division of Speech Pathology and Audiology, ${ }^{3}$ Research Institute of Audiology and Speech Pathology, \\ College of Natural Sciences, Hallym University, Chuncheon, Korea
}

\author{
환경 소음으로부터 지혜로운 대처를 위한 소음 지도 작성의 필요성 \\ 김 여 주 ${ }^{1,2} \cdot$ 한 우 재 ${ }^{1,23}$ \\ 한림대학교 자연과학대학 HearT 실험실', 언어청각학부, 청각언어연구소 ${ }^{3}$
}

\begin{abstract}
Since environmental noise, which has recently increased disputes and complaints, has a negative impact directly or indirectly on the lives of modern people, accurate analysis of noise effects and establishment of noise reduction method are essential. In the view of prevention, the noise map is very important for observing the overall noise distribution, identifying the noise sources, and preparing a noise reduction plan. In Korea, technical studies had conducted for producing the noise map. Various efforts also applied to prepare noise reduction measures, efficient introduction of regional noise maps, and establishment of management systems. However, there was a lack of experts and budgets to produce the noise map. The noise prediction formula and program were not standardized yet, consequently that it was difficult to build an infrastructure and update it. In this paper, by making a noise map for Chuncheon city using a smartphone application, we tried to produce a brief version of the noise maps which would increase people's perception and interest toward. Furthermore, we introduced several good examples of the noise map from other countries. We expect that it is possible to reduce social costs and to improve the quality of people's lives by academically approaching the multifaceted relationship between environmental noise, hearing, and health in Korea.
\end{abstract}

Key Words: Noise map, Environmental noise, Noise exposure, Noise management, Geographic information system.

Received: September 9, 2019 / Revised: September 25, 2019 / Accepted: September 25, 2019

Correspondence: Woojae Han, Laboratory of Hearing and Technology, Division of Speech Pathology and Audiology, \#8603 Natural Science Building, Hallym University, 1 Hallymdaehak-gil, Chuncheon 24252, Korea

Tel: +82-33-248-2216 / Fax: +82-33-256-3420 / E-mail: woojaehan@hallym.ac.kr

\section{INTRODUCTION}

현대화와 산업화로 인한 급속한 도시 개발은 인구의 도시 과 밀화 현상과 교통량의 증가를 야기하였고, 이로 인해 대부분의 도시들은 다양한 소음으로부터 소음 규제 기준 이상의 강도에 과다하게 노출되었다(Jung et al., 2007). 반면 사람들의 생활 수준은 점차 높아지고 타인으로부터 피해를 받지 않고 조용한 환경에서 살고 싶어하는 욕구가 증가함에 따라 소음(noise, 원 하지 않는 소리)의 발생으로 생겨나는 문제는 종종 사회적 이 슈로 떠오르고, 소음 관련 민원 역시 지속적으로 증가하고 있

(cc) This is an Open Access article distributed under the terms of the Creative Commons Attribution Non-Commercial License (https://creativecommons.org/licenses/by-nc/4.0) which permits unrestricted non-commercial use, distribution, and reproduction in any medium, provided the original work is properly cited.
다(Park \& Park, 2003).

최근 환경부에서는 도시의 소음을 체계적으로 관리하기 위 해서 소음 발생의 대표 지점에 환경소음측정망(소음 진동 측정 및 소음 통계 관리 시스템)을 설치하여 운영하고 있지만(Ministry of Environment, 2018), 해당 지역의 전반적인 소음의 측 정 및 파악이 쉽지 않고 소음도 이외의 추가 항목은 측정이 불 가능하다는 한계점이 있다(Sun, 2011). 이러한 문제들을 해결 하기 위한 하나의 방안으로써 소음 지도의 작성이 제안되었다. 소음 지도의 작성은 대상 지역의 소음 분포를 한눈에 파악할 수 있고 문제시되는 소음원의 위치가 쉽게 식별되기 때문에 사 전에 소음으로부터 영향 및 피해를 예측하고 관리할 수 있다 (Sun et al., 2009b). 현재 유럽에서는 Green Policy (유럽 환경 정책)를 통해 소음 지도 작성을 의무화하고 있으며, 작성된 소 
음 지도를 기반으로 소음 저감 방안을 포함한 소음 정책의 수 립에 많은 노력을 기울이고 있다. 또한 일본, 홍콩, 미국, 터키 등 많은 국가에서도 정부 차원에서 소음 지도를 구축하고 소음 관리의 기초 자료로 다양하게 활용하고 있다. 국내에서도 수년 전부터 소음 지도 제작의 필요성을 강조하며 소음 지도 작성 및 활용을 위한 법안을 제정하고 계획을 세웠으나, 인프라 구 축이 어렵고 대중들의 낮은 인식 문제로 소음 지도 제작에 상 당한 어려움을 겪고 있다. 따라서 본 논문에서는 환경 소음과 그로 인한 현대인의 삶의 질 관점에서 환경 소음에 관한 국내 외 기준을 조사하고, 소음 지도의 개념, 활용 방안, 관련 시행 령, 필요성에 대하여 분석하고자 한다. 궁극적으로는 국내의 소 음 지도 제작 활성화 및 실용화를 위하여 청각학적 관점에서 나아가야 할 연구 방향을 제안하고자 한다.

\section{BETTER UNDERSTANDING OF ENVIRONMENTAL NOISE}

\section{환경 소음으로 인한 현대인의 피해}

현대의 도시 환경은 교통 소음, 공장의 기계 및 설비 소음, 공 사장의 작업 소음, 생활 소음, 군중 소음, 확성기 또는 사이렌 소리 등 다양한 형태의 소음원이 존재하고 있으며, 이 중 가장 주된 소음원은 항공기, 철도, 자동차의 이동 시 발생하는 교통 소음이다(Ministry of Health and Welfare \& Korean Academy of Medical Sciences, 2015). 국내의 소음 허용 기준은 지역 에 따라 상이하지만 일반적으로 낮 시간은 50 70 dB(A)이고 밤 시간은 40 58 dB(A)이다. 허용 기준이 넘는 소음에 지속적 으로 노출될 경우 단기적으로는 수면 방해, 대화 및 청취 방해 등 일상 생활에 피해를 받게 되며, 집중력 및 작업 능률의 저하 등 직·간접적인 피해로 이어진다. 장기적으로는 소음성 난청의 원인이 되며 스트레스와 정신장애를 유발시킬 뿐만 아니라 생 리적, 사회적 기능까지 저하시키게 된다. 예를 들어 약 $70 \mathrm{~dB}$ 이
상의 소음 강도에 노출은 청각장애 이외에도 심혈관계 질환과 고혈압의 발생, 느리고 깊은 호흡, 말초혈관의 수축, 골격과 근 육의 긴장 변화 및 소변과 혈액 안의 화학적 변화 발생 등의 생 리적인 효과에 부정적인 영향을 준다(National Noise Information System, 2019). 또한 후천적 소음성 난청은 타인과의 사 회적 소통 제약, 인지기능의 저하, 사회적 고립감, 우울 및 낮은 자존감과 같은 정신적 문제를 일으켜 전반적인 삶의 질 저하와 경제 활동의 제약으로 이어질 수 있다(Ministry of Health and Welfare \& Korean Academy of Medical Sciences, 2015).

\section{국제 소음 권고 기준 및 나라별 환경 소음 기준}

세계보건기구(World Health Organization, WHO)에 따르면 현대인들의 건강 유지를 위한 야간 소음 가이드라인은 $40 \mathrm{~dB}(\mathrm{~A})$ 이며, 최대 $55 \mathrm{~dB}(\mathrm{~A})$ 로 잠정 기준치를 유지하도록 권장하고 있 다(World Health Organization, 2009). 더불어 WHO의 2018 년 환경 소음 지침에서는 주간과 야간의 시간을 구체적으로 구 분하여 허용 소음을 제시하고 있다. 한국, 일본, 독일, 영국의 국 가별 소음 환경 기준은 Table 1 에 제시된 것과 같이 각 국가마 다 약간의 차이는 존재한다. 예를 들어 일본의 도로변 지역 허 용 소음 기준은 최고 $65 \mathrm{~dB}(\mathrm{~A})$ 로 비교적 엄격하고 독일은 주 거 지역을 기준으로 야간의 기준이 상대적으로 낮게(혹은 엄격 하게) 설정되어 있다. 영국은 $\mathrm{WHO}$ 의 권고 기준을 참조하여 규 정하고 있으며 도로변 지역에 대한 소음 기준은 따로 제시하지 않고 있다. 국내의 경우 국제표준화기구(International Organization for Standardization, $\mathrm{ISO}$ )의 권고 기준을 참고하였으나 $5 \mathrm{~dB}(\mathrm{~A})$ 정도 완화된 규정을 사용하며 일본 및 영국과 대체로 유사하다.

\section{환경소음측정망의 도입}

환경 문제 중에서도 분쟁 및 민원이 잦고 해결이 간단하지 않은 소음 문제를 관리하기 위하여 국가적으로 법령 정비 및

Table 1. Criteria for recommended environmental noise levels in other countries

\begin{tabular}{|c|c|c|c|c|c|c|c|c|}
\hline \multirow{2}{*}{ Applied area } & \multicolumn{2}{|c|}{ Japan } & \multicolumn{2}{|c|}{ Germany } & \multicolumn{2}{|c|}{ United Kingdom } & \multicolumn{2}{|c|}{ Korea } \\
\hline & Day & Night & Day & Night & Day & Night & Day & Night \\
\hline \multicolumn{9}{|l|}{ General area } \\
\hline Dedicated residential area & 55 & 45 & 45 & 35 & 50 & 40 & 50 & 40 \\
\hline General residential area & 55 & 45 & $50-55$ & $35-40$ & $55-60$ & $45-50$ & 55 & 45 \\
\hline Commercial quasi-industrial area & 60 & 50 & $60-65$ & $45-50$ & 65 & 55 & 65 & 55 \\
\hline Industrial area & 60 & 50 & 70 & 70 & 70 & 60 & 70 & 65 \\
\hline \multicolumn{9}{|l|}{ Roadside area } \\
\hline Residential area & $60-65$ & $55-60$ & 65 & 55 & & & 65 & 55 \\
\hline Commercial quasi-industrial area & 65 & 60 & 70 & 60 & & & 70 & 60 \\
\hline Industrial area & 65 & 60 & 75 & 65 & & & 75 & 70 \\
\hline
\end{tabular}

Day time: 6 am-10 pm, Night time: 10 pm-6 am; Unit: Leq dB(A) 
정책의 수립을 추진하고 있다. 환경부는 전국의 지역별 소음 실 태를 체계적으로 파악하여 측정 방법을 표준화하고 측정 결과 에 대한 신뢰도 향상과 정확한 통계 자료를 확보하기 위해 소 음측정망을 운영하고 있다. 현재 국내 44개 도시를 기준으로 357 개 지역에 총 1,766 개의 환경소음측정망이 설치되어 있으며 이에 대한 정보는 국가소음정보시스템 홈페이지에서 확인할 수 있다(Ministry of Environment, 2018).

Table 2에 정리된 바와 같이 환경소음측정망은 실시간 소음 공개 및 현황 정보를 제공해 준다는 장점이 있지만, 측정 지역 이 한정적이며 구체적인 소음원의 파악이 어렵고 소음도 이외 의 추가 항목은 측정이 불가능하기에 소음 환경 정책의 기본 자료로 활용하기에는 한계가 있다. 따라서 대안으로 환경소음 측정망을 소음 지도에 연계할 경우 소음측정망이 설치되어 있 지 않은 지점에서의 소음 측정이 가능해짐으로써 소음측정망 의 실측 자료와 발생원별 소음 지도 데이터를 비교하여 예측 소음도의 타당성 검토가 가능하며 구체적인 소음원 파악이 가 능해진다. 수치를 활용하여 단편적으로 제시되던 환경소음측 정망 데이터에 전체적인 소음 분포도 관찰이 가능한 소음 지도 를 보완할 경우 소음 지도의 정밀도를 높이고 소음 저감 대책 마련 등 데이터의 활용도(소음 노출 인구 산정, 소음원별 소음
지도 제작)를 향상시킬 수 있다(Park et al., 2007).

\section{DEFINITION OF NOISE MAP}

\section{개념 및 특징}

소음 지도(noise map)는 이론적으로 증명된 소음 예측식, 실 험상의 결과로 얻은 경험식, 지리정보시스템(geographic information system, GIS) 등을 활용하여 소음의 수치와 분포를 계 산하고 그에 따른 데이터를 분석 및 가공하여 제시하는 것이다 (Park \& Park, 2005). 소음 지도는 일정한 지역을 대상으로 소 음을 측정하여 등음선이나 색을 이용해 시각화함으로써 기존 에 수치로만 표현되던 소음도와 달리 소음에 대한 영향을 한눈 에 파악하고 효율적으로 평가할 수 있는 도구이다(Sun et al., 2009a). 소음 지도는 작성 방법에 따라 GIS의 공간 분석을 이 용한 소음 지도와 소음 예측식을 적용한 소음 지도로 구분할 수 있다. GIS의 공간 분석을 이용한 소음 지도는 대상 지역의 소음 측정 데이터와 지형의 정보를 결합하여 데이터베이스를 생성하고, 이를 공간 분석(spatial analysis)을 통하여 소음도로 나타낸다. 반면, 소음 예측식을 적용한 소음 지도는 상용화된 소프트웨어를 이용하여 소음에 영향을 줄 수 있는 인자를 중

Table 2. Pros and cons between environmental noise auto-measurement and noise map

\begin{tabular}{|c|c|c|}
\hline Advantages & Limitations & Suggestion \\
\hline $\begin{array}{l}\text { nvironmental noise automatic measurement network } \\
\text { - General status information } \\
\text { - Policy support resources } \\
\text { - Policy promotional effect } \\
\text { - High noise level area surveillance at ordinary times } \\
\text { - Real-time disclosure (electronic display system) } \\
\text { - Noise level feasibility study data }\end{array}$ & $\begin{array}{l}\text { Local environment (display noise } \\
\text { level at installation point only) } \\
\text { Difficulty in selecting areas } \\
\text { to install first } \\
\text { High price for measuring } \\
\text { equipment } \\
\text { High installation and management } \\
\text { costs } \\
\text { Additional items other than noise } \\
\text { cannot be measured }\end{array}$ & $\begin{array}{l}\text { Unifying of measurement point } \\
\text { coordinate notation } \\
\text { Addition of traffic and vehicle } \\
\text { speed measuring equipment } \\
\text { Adding weather measuring } \\
\text { equipment } \\
\text { Necessity for localization of } \\
\text { measuring equipment }\end{array}$ \\
\hline $\begin{array}{l}\text { Noise map } \\
\text { - Subdivided status information by region } \\
\text { - Determination of priority for establishment } \\
\text { of reduction strategy } \\
\text { - Impact by causes } \\
\text { - Predictable according to the background and elevation } \\
\text { of building } \\
\text { - Predictable of noise level according to traffic change } \\
\text { - Furnish data of policy promotion and policy support }\end{array}$ & $\begin{array}{l}\text { Various databases are required } \\
\text { for production } \\
\text { Absence of developed predictive } \\
\text { formula in Korea } \\
\text { Absence of developed software } \\
\text { for dedicated noise maps } \\
\text { in Korea } \\
\text { Lack of noise maps production } \\
\text { personnel and manufacturing } \\
\text { institutions }\end{array}$ & $\begin{array}{l}\text { Generating information on the } \\
\text { automatic environmental noise } \\
\text { measurement network when } \\
\text { making noise maps (geopolitical } \\
\text { position) } \\
\text { Development of predictive formula } \\
\text { and software appropriate } \\
\text { to domestic circumstances } \\
\text { Come up with an environmental } \\
\text { noise automatic measurement } \\
\text { network data compatible plan }\end{array}$ \\
\hline
\end{tabular}


심으로 발생원 주변의 소음도를 예측하여 생성하는 지도이다 (Choi, 2010). 환경부 고시 제2016-117조에 의하면 국내 도로의 소음 예측식은 CRTN, RLS90, NMPB, Nord 2000, ASJ 2003 을, 철도 소음 예측식은 Schall03, CRN, Nord 2000을 따르며, 그 외 예측식에 대해서는 국립 환경과학원의 검증을 거쳐 사용 할 수 있다.

간단한 이해를 위해 스마트폰 소음 측정 어플리케이션을 활 용하여 저자들이 거주하는 춘천시 소음 지도를 작성해 보았다. 어플리케이션은 접근의 유용성을 위해 다운로드 수가 가장 높 고 오차 보정이 가능한 '소음 측정기' 어플리케이션과 '사운드 미터 및 소음 감지기' 어플리케이션으로 선정하였다. 국내와 국 외에서 다양한 스마트폰 소음 측정 어플리케이션을 활용하여 소음 측정을 실시하고 있으며(Guillaume et al., 2016), 어플리 케이션은 오차 보정을 잘 실시할 경우 측정 오차가 $\pm 2 \mathrm{~dB}$ 이내 로 정확성 확보가 가능한 것으로 나타났다(Ma \& Park, 2013). 유럽에서는 'noise capture'라는 스마트폰 어플리케이션을 활용 한 소음 지도를 정책에 활용하고 있다(Picaut el al., 2017). 아직 까지는 스마트폰을 활용한 소음 측정 가이드라인이 국내·외적 으로 존재하지는 않지만 비슷한 기법을 활용한 선행연구에서 는 10 초 이상 혹은 2 분 이상으로 다소 상이한 측정 기준을 적 용하고 있다(Guillaume et al., 2016). 본 연구에서는 좀 더 안정 적이고 객관화된 데이터 수집을 위해 어플리케이션의 마이크
를 방음실에서 소음측정기(Sound Level Meter, Type 2250, Bruel \& Kjaer, Naerum, Denmark)로 보정한 후, 환경 소음의 변화 폭을 충분히 고려하며 신뢰도를 확보하기 위해 낮 시간 동안 동일 장소에서 약 15 분가량 소음을 두 번씩 반복 측정하였 고, 측정한 소음의 평균값을 기준으로 소음 지도를 제작하였다. 춘천시의 소양동, 후평 1 동· 2 동· 3 동, 조운동, 효자 1 동·2동. 3 동, 약사 명동, 강남동, 퇴계동, 석사동, 교동 지역을 대상으로 총 133 개 지점에서 소음을 측정하여 Figure 1과 같이 제작하였 다. 소음 등급 기준은 noise level in $\mathrm{dB}(\mathrm{A})$ 를 기준으로 0 52 $\mathrm{dB}(\mathrm{A}), 52 \sim 64 \mathrm{~dB}(\mathrm{~A}), 64 \mathrm{~dB}(\mathrm{~A})$ 이상으로 분류하였다(Seong et al., 2011). 복합상가, 주택가, 학교, 병원, 공사장 등 일반 주거 지역과 철도 및 도로변 지역을 중심으로 소음을 측정한 결과 133 개의 측정 지점들 중 총 50 개의 지점에서 $64 \mathrm{~dB}(\mathrm{~A})$ 이상의 소음 강도가 측정되었다. 소음이 심할 것이라고 예상했던 행사 장, 철도, 실외기, 공사장과 상대적으로 조용할 것으로 예상했 던 주거 지역이나 병원 및 학교 근처에서도 $64 \mathrm{~dB}(\mathrm{~A})$ 이상의 소음에 노출되고 있음을 시각적으로 빠르게 분석할 수 있었다. 또한 춘천시청에 제기되고 있는 소음 관련 민원인 공사장 소음, 실외기 소음, 집회 소음 발생 장소 역시 예상대로 소음의 정도 가 매우 심한 것으로 확인되었다.

이처럼 소음 지도를 작성할 경우 기존 수식에 의존하던 예측 소음도와 달리, 소음 영향에 대한 지역적 분석을 통해 보다 광

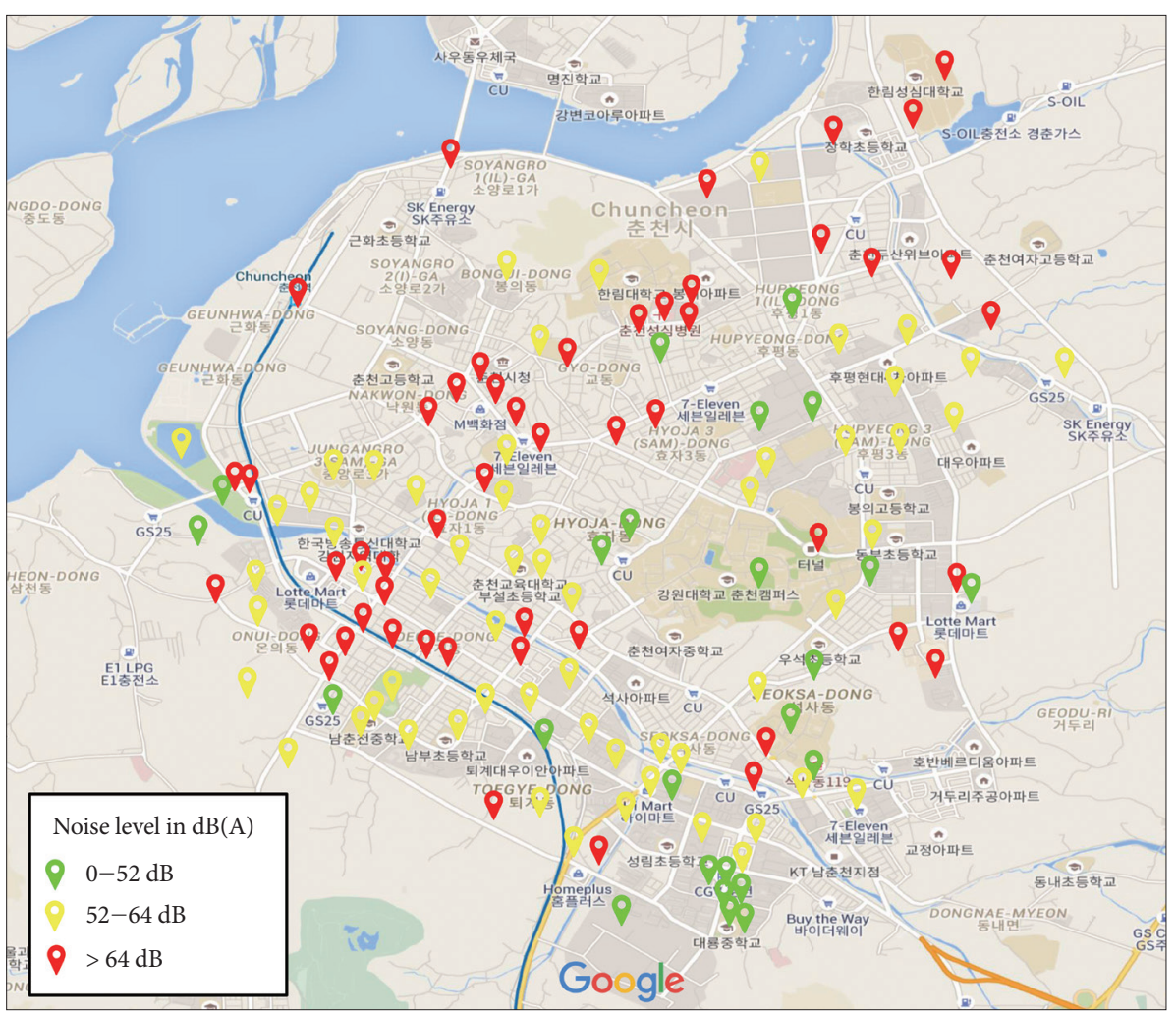

Figure 1. A brief version of noise map for Chuncheon city recorded in October 2018. It has three classifications to be appropriate (green marks), a little bit loud (yellow marks), and bothersome noise levels (red marks) in terms of $\mathrm{dB}(\mathrm{A})$. 
역적인 평가와 다목적 해석이 가능해진다. 따라서 전체적인 소 음 분포도 관찰은 지역에서 문제시될 수 있는 소음원을 찾아내 고, 해당 소음원의 영향 및 정도를 예측 자료로 활용 가능하다. 뿐만 아니라 환경 소음에 대한 공간적인 분포의 관찰이 가능하 여 건물의 건설과 지역 개발을 계획하는 데 기초 자료로 활용 될 수 있으며, 환경 소음 평가 시 체계적인 대안의 수립이 가능 해지고 문제가 되는 지점을 미리 파악하여 그에 합당한 대책을 실행하는 데 도움을 줄 수 있다(Sun et al., 2009b). 그러나 소 음 지도는 실시간으로 변화하며 복잡한 양상을 나타내는 소음 의 전반적인 상황을 예측하여 소음 현황을 정확하게 나타내는 데 한계가 있으므로 불가피한 오차가 발생할 수도 있고, 대상 지역의 범위가 넓거나 소음 예측의 정확도를 향상시켜야 하는 경우 지도 제작을 위한 자료 수집 및 분석이 방대하여 분석 및 계산 기간의 장기화를 가져올 수 있다(Park et al., 2007b). 더불 어 소음 지도 제작 결과의 공개는 새로운 민원의 발생이나 지가 하락 등을 포함한 부가적인 사회적 문제가 발생할 여지도 간과 할 수는 없다(Sun, 2010).

\section{활용 방안}

소음 지도는 대상 지역의 소음의 영향을 시각화하여 한눈에 알아볼 수 있고 효과적인 소음 관리를 위한 정보를 신속하게 제공할 수 있다는 장점으로 그 중요성이 점차 증가하고 있다. 소음 지도를 제작하면 대상 지역의 소음 현황을 효과적으로 파악할 수 있으며 다양한 소음원이 혼재되어 있는 지역에서 주 소음원 결정이 가능해진다. 기존의 소음 노출 인구 조사는 주 로 설문 조사나 경험적 계산식과 같은 주관적 자료를 기반으로 하였다. 만약 소음 지도를 제작할 경우 객관적 데이터를 확보할 수 있으며 기존의 방법에 비해 공간-시간적 제약을 받지 않게 된다. 따라서 작성된 소음 지도는 소음 저감 대책의 데이터로 활용될 수 있으며 토지의 이용이나 건물 건축 계획 시 환경영 향평가에도 중요한 근거 자료가 된다. 또한 국가의 정책적인 측 면에서 소음 관련 법령의 기준 재정비나 새로운 법령 제정 시 기 초 자료로 활용이 가능하며, 전략적 소음 지도(strategic noise $\mathrm{map})$ 의 제작을 통해 도시의 계획 단계에서부터 소음도를 예측 하여 보다 쾌적하고 정온한 환경의 유지와 함께 친환경적·에너 지 절약형 도시의 개발을 가능하게 함으로써 소음 문제를 사전 에 예방할 수 있다(Park et al., 2007).

\section{소음 지도 관련 국내 시행령}

2017년 개정된 소음진동관리법의 제4조의 2항 「소음 지도의 작성」에 따르면 환경부장관 또는 시·도지사가 환경 소음 관리 및 소음 저감이 필요하다고 인정하는 경우 소음 지도를 작성할 수 있도록 허가하고 있다. 2016년 개정된 소음 지도의 작성 방
법(환경부 고시 제2016-117)에서 정한 소음 지도 대상 소음원은 도로 및 철도 소음이며, 소음 지도를 작성할 수 있는 기관은 「환 경영향평가법」에 의한 환경영향평가대행자, 「환경분야 시험·검 사 등에 관한 법률에 의한 소음-진동측정대행업자, 「환경기술 개발 및 지원에 관한 법률」에 의한 소음·진동방지시설업자, 「기 술사법」에 의한 소음·진동 기술사 사무소, 「엔지니어링기술 진 흥법」에 의한 소음·진동 분야 엔지니어링 활동 주체, 「산업교육 진흥 및 산학협력촉진에 관한 법률에 의한 산학협력단, 그 밖 에 환경부장관이 인정하는 기관으로 지정되어 있다.

소음 지도 작성 프로그램은 작성 대상 지역을 3 차원으로 표 현할 수 있으며, 소음원을 생성할 수 있고 도로 및 철도의 소음 예측식 및 예측 조건 등의 설정이 가능해야 한다. 또한 소음 지 도는 5년마다 갱신해야 하며 도로나 철도의 개설 또는 폐쇄, 교 통량의 현격한 변화, 대단위 주거 지역이 개발되었거나, 기타 지 방자치단체의 장이 필요하다고 판단되는 경우에 수정 또는 재 작성이 가능하다(Koh et al., 2016).

\section{DEVELOPMENT OF NOISE MAP AND ITS NECESSITY}

\section{국내 소음 지도의 현주소-사례를 중심으로}

국내에서도 행정구역별 소음 지도를 보급하기 위해 소음 예 측식, 표준 방안 및 소음 지도 제작 프로그램 검토, 소음 노출 의 인구 산정 방법을 제시하고, 소음 지도 법제화를 위한 정책 을 수립하여 2007년부터 환경소음측정망 확충과 함께 지역별 인구수에 따라 점차적으로 확대하며 소음 지도를 도입할 계획 이었다. 그러나 환경부에서는 현재 소음 지도를 제작할 수 있는 전문가의 미지정과 많은 예산 지출로 인해 인프라 구축이 어려 워 지도의 갱신이 5년 주기로 진행되지 않기에 소음 지도의 신 뢰도 및 실용화가 어려운 실정이다(Jang \& Jeon, 2005). 게다가 소음 지도 제작을 민간 업체에 맡기다 보니 정확도와 정밀도가 떨어지고 부실 작성에 대한 검증과 사후관리도 전혀 이루어지 지 않고 있다(Sun et al., 2009b). 현재 소음 지도를 작성해 정책 결정 도구로 활용하고 있는 지자체의 경우에도 민원 폭주, 부 동산 투기 등으로 인해 소음 지도 공개를 꺼려하고 있다. 실정 이 이렇다 보니 국가에서 예산을 지원해 준다고 하여도 시에서 만들려고 하지 않아 소음 지도 제작이 계속 미뤄지고 있으며 지속적인 업데이트를 원하는 지자체는 운영할 수 있는 인력 부 족으로 어려움을 겪고 있다(Son et al., 2008).

현재까지 국내에서는 도로 등 단일 소음에 대한 국지적인 소 음 현상 파악과 소음 대책의 효과를 예측하기 위한 목적으로 소음 지도가 작성된 사례가 대부분이다. 도시 전체를 포함한 소음 지도가 제작된 것은 2007년 청주시가 처음이고, 2008년 
서울시 영등포구 등에서 GIS 기반의 소음 지도를 제작한 바 있 다. 구체적으로 2007년 3월 청주시는 도로 교통 소음을 포함하 여 환경 소음 문제를 해결하기 위한 방안으로 청주시 전체를 대상으로 하는 소음 지도를 제작하였다. 작성된 소음 지도는 철 도 및 항공기, 공사장, 건물 배치 형태에 따른 운영 시 three-dimensional (3D) 소음 지도를 제작하여 소음에 대한 영향을 파 악하는 데 효과적으로 이용되고 있다. 소음 지도 작성 결과의 분석을 통해 단계별 소음 저감 대책 수립 및 소음의 실시간 관 리 등의 계획을 세웠으나, 후속 과제나 전담팀의 부재로 지속적 인 소음 지도의 업데이트가 불가능하여 효과적으로 이용되지 못하고 있는 것으로 조사되었다. 2008년 4월 서울시 영등포구 는 소음 저감 대책 및 다양한 소음 노출 정책 결정 등에 도움을 주기 위해 약 1 년에 걸쳐 서울시 자치구 중 처음으로 영등포구 전체를 대상으로 하는 소음 지도를 제작하였다. 그러나 안타깝 게도 후속 과제의 부재 등으로 지속적인 업데이트가 되지 못하 였으며 현재는 데이터베이스조차 확인할 수 없는 상황이다.

한편 원주시는 주요 도로를 대상으로 GIS의 공간 분석을 이 용한 소음 지도와 소음 예측식을 적용한 소음 지도를 작성하였 다. 소음 예측식을 적용한 원주시 소음 지도는 플래시 형태로 제작되어 원주시 웹사이트를 통해 공개하였으나 현재는 삭제된 상황이다. 충주시의 소음 지도는 용도 지역별로 환경 기준을 초과하는 곳을 기반으로 초과소음 지도를 제작하였으며, 초과 소음 면적을 산정하여 철도 소음 지도 및 주요 도로와 간선도 로를 대상으로 도로 교통 소음 지도를 제작하였다. 또한 서울 시 중랑구는 도로 교통 소음과 철도 소음에 대한 소음 지도를 작성하였으며 중랑구 지역의 주요 도로와 철도에 의한 소음의 영향을 각각 예측하고, 이를 비교하여 주 소음원을 분석하였 다. 위에서 언급한 국내의 주요 5 개 소음 지도의 작성 사례는 Table 3에 보다 자세히 정리하였다. 요약해 보면 국내의 행정구 역별 소음 지도의 소프트웨어와 소음 예측식은 국외 기술에 의존하고 있고 전반적으로 표준화되지 않아 상호 간의 객관적 인 비교가 어렵다. 또한 측정 소음원 및 입력 인자도 통일되지 않아 소음 저감 대책 및 다양한 정책의 기초 자료로 활용하는 데 아직까지는 많은 한계가 있다.

\section{국외 소음 지도의 작성 및 우수 사례}

국외의 경우 약 30 년 전부터 소음 지도 작성을 통해 도로, 철 도, 공항 등의 교통시설로 인한 소음 영향을 파악하고 저감 방 안을 포함한 소음 정책의 수립에 많은 노력을 기울이고 있다. 소음 지도 제작이 활발하게 이루어지고 있는 대표적인 곳은 유 럽연합의 27 개 국가이며 이외에도 체코, 홍콩, 네덜란드, 터키, 일본 등에서 도로와 철도 주변에서 GIS와 연계하여 소음 지도 를 작성한 바 있다(Jo, 2013).
1990년대에 유럽 각국의 소음 저감을 위한 정책 수립의 목적 으로 소음 지도가 제시된 이후 2000년대에 들어 유럽의회에서 는 장기적인 소음 정책의 발전을 위하여 소음 관리 지침인 $\mathrm{Di}^{-}$ rective 2002/49/EC를 채택하였다(Sun \& Park, 2006). 이후 Green Policy를 발표하여 지역 인구수에 따라 소음 지도 제작 을 의무화하고 있다. 유럽연합의 소음 지도 작성에는 특정한 환 경 소음 기준 지표인 낮, 저녁, 밤의 시간으로 구분하여 소음에 대한 불쾌감을 주관적으로 표현하는 성가심의 정도를 평가하 는 척도 $55 \mathrm{~dB}$ day-evening-night sound level ( $\mathrm{L}$ den), 수면 장애를 평가하는 척도 $50 \mathrm{~dB}$ night sound level (L night)이 적 용된다. $\mathrm{dB} \mathrm{L} \mathrm{den은} \mathrm{하루를} \mathrm{기준으로} \mathrm{야간(23:00} \mathrm{7:00)} \mathrm{시간대}$ 에 $10 \mathrm{~dB}(\mathrm{~A})$ 의 가중치를, 저녁(19:00 23:00) 시간대에는 5 $\mathrm{dB}(\mathrm{A})$ 의 추가적인 가중치를 적용한 하루 동안의 등가소음수 준(Leq) 평가 단위이다. $\mathrm{dB}$ L night는 야간(23:00 7:00) 시간 대의 등가소음수준(Leq) 평가 단위이다. 앞서 사용한 단위인 $\mathrm{dB}(\mathrm{A})$ 는 사람의 귀로 들을 수 있는 음의 크기를 주파수에 대 한 가중치 필터를 적용하여 상대적인 단위 $(\mathrm{dB})$ 로 나타낸 값으 로 소음 노출로 인한 피해를 나타내는 지표인 $\mathrm{dB} \mathrm{L} \mathrm{den,} \mathrm{dB} \mathrm{L}$ night와는 다른 개념이다. 소음 지도에 포함되어야 할 필수 정 보, 주요 소음원, 특정 지역에 대한 소음도(학교, 병원, 주거지 등), 정보 공개 및 실행 계획의 기초 자료로 활용하기 위한 추가 정보 등의 내용을 포함해야 하며, 필요 시 또는 5년마다 재작성 해야 한다. 아울러 소음 지도 결과를 활용하여 선정한 소음 영 향이 적은 정온 지역(quiet area)은 보존하고, 소음 노출이 과다 한 지역에 대해서는 소음 저감 대책을 수립하는 등 장기적 소 음 관리 계획을 마련하도록 하고 있다(Sun et al., 2009a). 보다 정밀한 소음 지도 작성을 위하여 기술적·재정적 투자를 확대 하고 있으며, HARMONOISE, IMAGINE 등의 산·학·연 컨 소시엄을 구성하여 활발한 논의를 진행하고 있다(Choi, 2010).

적극적인 활용 사례의 예로, 영국 웨일스는 지역 주민들에 대한 환경 소음의 영향을 최소화할 수 있는 정책적이면서 기술 적인 방안들을 모색하기 위해 전략 소음 지도(소음 저감 대책용) 를 제작하고 있다. 도로 교통 및 철도 소음에 대해서는 주변 토 지 이용 계획과의 연계를 통한 저소음 교통 계획, 확장 및 변경 계획이 있는 도로 및 철도 노선에 대한 저감 시스템 개선 등의 대책을 마련하고 있다. 산업 지역의 관리에 대해서는 단기적이면 서 불연속적인 소음의 특징을 고려하여 실행 계획 우선 지역 후 보지를 지정하는 방안보다는 기존의 산업 지역에서 발생하는 소음의 영향을 저감할 수 있는 대책을 마련하고 있다(Welsh Government, 2013). 또한 정부기관에서는 5년의 실행 계획 기 간 이상으로 진행되어야 하는 환경 소음 관리의 장기적인 관점 을 인식하여 대중에 대한 정보의 향상, 소음 영향에 대한 기초 근거 향상, 유럽연합과의 공조, 평가 방법의 개정, 실행 계획의 
Y Kim \& W Han

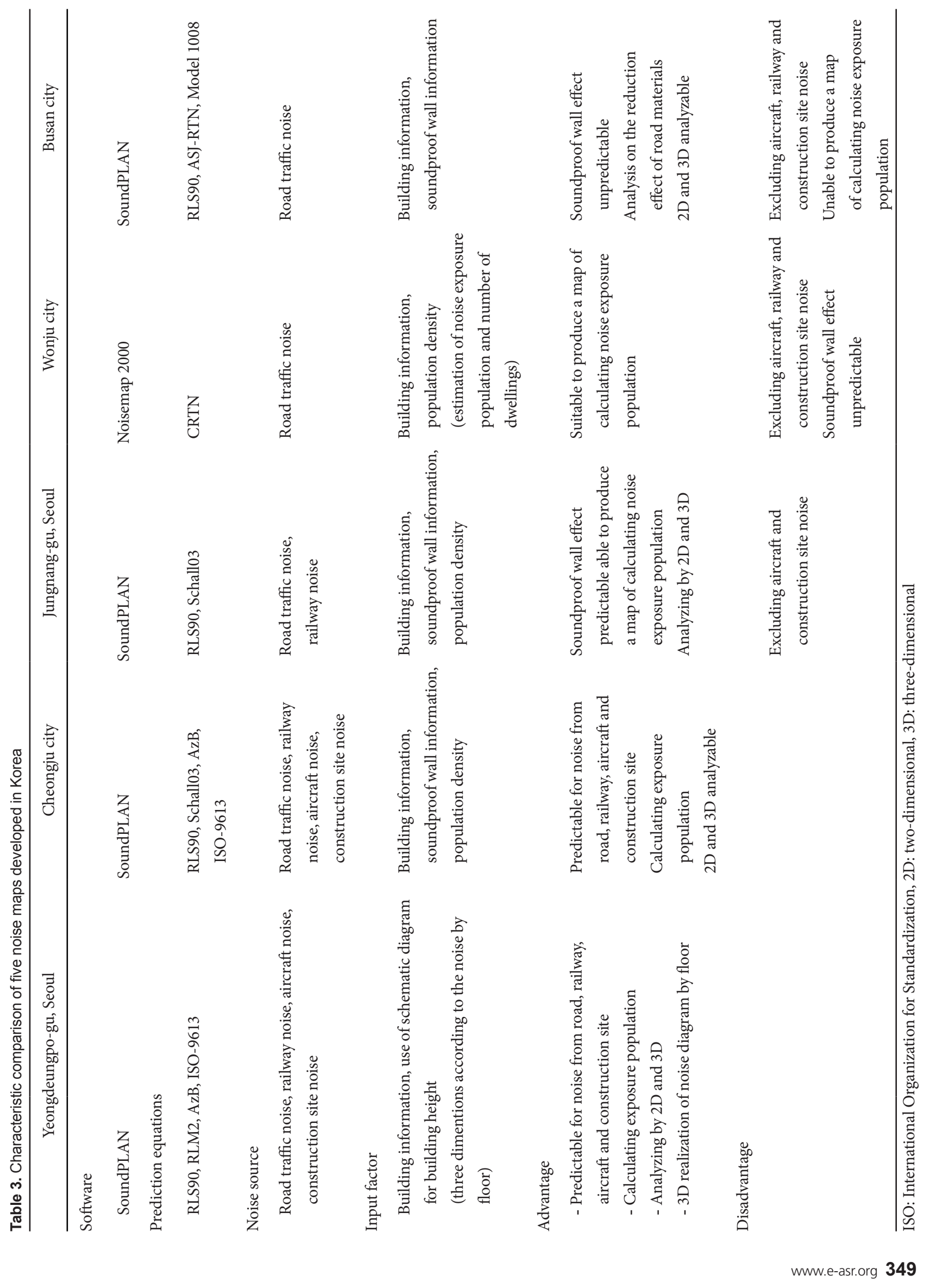


검토 등 쟁점에 대해 고려하도록 하고 있다(Sun, 2011).

한편 홍콩의 소음 지도는 GIS를 이용하여 도로 교통 소음을 평가하고 3D facade map (외벽 소음 지도)으로 작성하였으며, 이를 바탕으로 소음 노출 인구를 산정하였다. Survey \& Mapping Office (홍콩의 지형 정보를 담당하는 부서)에서는 디지 털 수치 지도를 제공받아 디지털 지형도를 작성하고, 도로망, 빌딩의 위치와 높이, 방음벽과 방음 터널, 인구 정보 등을 제공 받아 $3 \mathrm{D}$ 로 표현하였다. 주거용으로 사용하는 건물을 확인하 고, 인구 정보로부터 각 건물에 인구를 할당한 소음도와 건물 외벽의 높이에 따라 소음 노출 정도를 평가하였으며, 소음 지도 를 소음 저감 정책에 사용하기 위해 방음벽 시공 전과 후의 소 음도를 모델링하여 예측하였다. 체코 프라하에서는 1976년부터 5년 주기로 도로 및 철도 소음에 대한 소음 지도를 제작하였으 며, 도로와 철도로 인한 소음도 및 각 수음점에서의 소음도, 소 음 노출 인구수, 소음 노출 인구 비율을 알 수 있도록 작성하였 다. 네덜란드 암스테르담은 정부와 지역 단체에서 소음 지도를 작성하고 있으며, 주요 철도, 도로, 공항의 소음 자료와 GIS 측 정 결과를 이용하여 매년 갱신하고 있다. 제작된 소음 지도는 도시 계획 시 아파트나 대규모 상업 단지 건설에 있어서 중요한 기초 자료가 되며, 신축 건물의 배치 및 높이의 결정과 소음원 대책 마련을 위한 자료로 활용된다(Jo, 2013).

\section{CONCLUSIONS}

최근 분쟁과 민원이 증가되고 있는 소음은 현대인의 삶에 직·간접적으로 부정적인 영향을 주고 있기에 소음 영향에 대 한 정확한 분석 및 소음 저감 대책 수립이 필수적이다. 소음 지 도는 전체적인 소음 분포도의 관찰 및 소음원을 파악하고 사전 의 예방적 차원에서 소음 저감 방안 마련의 중요한 근거 자료이 다. 국내에서도 소음 지도를 제작하기 위한 기술적 연구가 학계 에서 지속적으로 이루어지고 있으며 소음 저감 대책, 지역별 소 음 지도의 효율적 도입 및 관리 체계의 구축 방안 마련 등을 위 해 다양한 노력을 기울이고 있다. 그러나 현재 소음 지도를 제작 할 전문가와 예산 부족으로 인프라 구축이 어렵고 업데이트도 제대로 이루어지지 않아 실용화가 어려운 실정이다. 또한 소음 예측식 및 프로그램의 국내 표준화가 되어 있지 않고 민간 업체 에 위탁하다 보니 정확도와 정밀도가 떨어지고 사후관리도 제 대로 이루어지지 않고 있다.

반면, 소음 지도의 제작 및 실용화가 잘 실행되고 있는 유럽 의 경우 Green Policy를 통해 소음 지도의 제작을 의무화하고 있으며, 소음의 객관적인 데이터를 확인할 수 있는 국가 소음 현황 시트를 작성해 공개하고 있다. 유럽에서는 소음 문제 개선 을 위해 국가적인 차원에서도 다양한 노력을 기울이고 있으며,
특히 일반 대중의 참여를 활성화시킴으로써 인프라 구축 문제 를 해결하고 보다 현실적이고 실용적인 정보를 수집하기 위한 방안을 모색하고 있다. 그중 대표적인 예가 스마트폰 어플리케 이션을 활용한 소음 지도이다. 유럽에서는 ISO 규준을 기반으로 한 'noise capture'라는 어플리케이션을 지정하여 소음을 측정하 고, 이를 바탕으로 소음 지도를 작성하기 위한 공간 데이터 인프 라인 OnoM@p에 활용하는 방안을 환경 소음 지침 2002/29/ CE에 포함시키고 있다(Picaut et al., 2017). 이러한 어플리케이션 은 저비용의 개방형 플랫폼으로 대중들의 소음에 대한 관심도 를 향상시키고 주기적인 데이터 업로드를 통해 5년 단위로 제정 되는 소음 지도의 한계점을 보완하며 실시간으로 소음 수준을 시각화하여 도시 지역뿐만 아니라 모든 지역의 탐색을 가능하 게 한다. 유럽에서는 대중들의 참여를 위해 접근이 용이하고 다 양한 데이터의 수집이 가능한 모바일 어플리케이션에 대해 지 속적으로 연구하고 있다(Radicchi, 2018).

본 논문에서는 스마트폰에 쉽게 접근할 수 있는 어플리케이 션을 활용하여 춘천시를 대상으로 소음 지도를 작성함으로써 국내의 실정에 맞는 소음 지도 제작에 한걸음 다가가고, 국민들 의 소음에 대한 인식 개선 및 관심도를 높여 접근할 수 있는 가능성을 열고자 하였다. 현재 국내의 상황은 소음 지도를 제 작하기 위한 전문가 및 예산 부족으로 인프라 구축이 어렵고 소음 지도를 제작하여도 대중들의 낮은 인식과 정부의 공개를 꺼려하는 경우가 대다수이다. 또한 법적으로 5년 주기의 소음 지도를 개정하도록 하다 보니 2 3년으로 제한되는 공사나 일시 적으로 발생하는 소음은 소음 지도에 반영되지 않는 한계점도 발생한다. 그럼에도 소음 지도 작성에 조금 더 개방적으로 접근 하기 위해 스마트폰을 활용하여 작성 가능한 소음 지도 어플리 케이션을 개발하고 국민들의 참여를 활성화시키며 적극적으로 활용한다면 전문가 부족, 인프라 결여, 소음 지도의 미완성, 소 음 관련 민원 등과 같이 현재 발생하고 있는 문제들을 해결하 는 데 일조할 것이다. 구체적 일례로 군공항의 소음 피해 지도 를 만들어 향후 소음법 제정에 주민 피해의 근거가 될 수 있겠 다. 더불어 국내의 소음 지도 제작 활성화 및 실용화를 위하여 기존에 국한되었던 직업적 소음 노출과 난청의 지엽적 문제에서 벗어나 환경 소음-청각-건강의 다각적 관계를 학문적으로 접 근하여 사회적 비용 절감은 물론 국민들의 삶의 질의 향상을 기대한다.

중심 단어 : 소음 지도·환경 소음·소음 노출·소음 관리·지리 정보시스템.

\section{Ethical Statement}

N/A 


\section{Acknowledgments}

Authors thank all students who took the 2018 Fall class of Industrial Audiology at Hallym University for their time and effort to record the environmental noise in Chuncheon city.

\section{Declaration of Conflicting Interests}

There are no conflict of interests.

\section{Funding}

This research was completed while being supported by National Research Foundation of Korea (NRF-2017R1A1A1A05001299).

\section{Author Contributions}

Y.K. and W.H. designed this manuscript. Y.K. systematically searched and analyzed information from various resources. Y.K. and W.H. organized the information and wrote the paper. W.H. reviewed the final version of the paper as the corresponding author.

\section{ORCID iDs}

Yeoju Kim

Woojae Han

https://orcid.org/0000-0002-3358-5100 https://orcid.org/0000-0003-1623-9676

\section{REFERENCES}

Choi, J. H. (2010, June). Creating Noise Maps for Basic Research in Daegu Noise Management. Daegu Gyeongbuk Development Institute (DGI). Retrieved from www.dgi.re.kr/Report/Detail?cd=1120000\&seq=1\&rSeq=2010060000207.

Guillaume, G., Can, A., Petit, G., Fortin, N., Palominos, S., Gauvreau, B., et al. (2016). Noise Mapping Based on Participative Measurements. Noise Mapping. Retrieved from https://www.degruyter.com/downloadpdf/j/ noise.2016.3.issue-1/noise-2016-0011/noise-2016-0011.pdf.

Jang, S. I. \& Jeon, H. J. (2005, November 17). Proceedings of the Korean Society for Noise and Vibration Engineering conference: Current Situation of Noise Map Manufacture in Foreign Countries and Its Application to Domestic Noise Map. Muju, Jeonbuk: Muju Resort.

Jo, K. D. (2013). A Study on the Efficient Introduction and Management System of Noise Indicators. The Incheon Institute. Retrieved from http://www.idi.re.kr/researchRPT/view.do?seq=1075\&iNum=844\&m= 0101\&s=idim.

Jung, W. H., Park, I. S., Kim, J. Y., Park, S. K., \& Kang, D. J. (2007, May 10). Proceedings of the Korean Society for Noise and Vibration Engineering conference: A Study on Standard Procedure of Road Traffic Noise Map. Cheongju, Chungbuk: Grandplaza Hotel.

Koh, H. I., Jang, J. W., Jang, S. H., \& Hong, J. Y. (2016). Analysis of the railway noise prediction result using Schall03 in noise mapping. Journal of Environmental Impact Assessment, 25(3), 175-189.

Ma, H. R. \& Park, D. Y. (2013). Evaluation on accuracy of noise measurement applications for iPhone 4 and iPhone 3Gs. Journal of the Korean Society of Safety, 28(1), 24-28.

Ministry of Environment. (2018). Integrated Operation Guide for Noise and Vibration measuring Network (2018). Ministry of Environment. Retrieved from http://www.me.go.kr/home/web/policy_data/read.do?pager Offset $=0$ \&maxPageItems $=10$ \&maxIndexPages $=10$ \&searchKey $=\&$ search
Value $=\&$ menuId $=10259 \&$ orgCd $=\&$ condition.deleteYn $=\mathrm{N} \&$ seq $=7228$.

Ministry of Health and Welfare \& Korean Academy of Medical Sciences. (2015, October 13). The Noise of the Life. Korea Centers for Disease Control \& Prevention (KCDC). Retrieved from http://health.cdc.go.kr/ health/HealthInfoArea/HealthInfo/View.do?idx=14270\&subIdx=1.

National Noise Information System. (2019). Noise Information. National Noise Information System. Retrieved from http://www.noiseinfo.or.kr/ about/info.jsp?pageNo=942.

Park, I. S. \& Park, S. K. (2003). Proceedings of the KSNVE annual spring conference: A Study on the Development of Noise Map for Quiet Environment of Urban Areas. Mokpo, Jeonnam: Second Engineering Museum of Mokpo Maritime University.

Park, I. S. \& Park, S. K. (2005). A study on the assessment method of noise exposure population using the over-ride value noise map. Transactions of the Korean Society for Noise and Vibration Engineering, 15(7), 859864.

Park, S. K., Lee, S. K., Kim, H. I., Kwon, D. M., Park, I. S., Kim, G. T., et al. (2007). A Study on the Preparation of Noise Map. Research Report of the Korea Society of Noise and Vibration Engineers. Retrieved from http:// webbook.me.go.kr/DLi-File/NIER/06/168233.pdf.

Picaut, J., Aumond, P., Can, A., Fortin, N., Gauvreau, B., Bocher, E., et al. (2017, June 10). Noise Mapping Based on Participative Measurements with a Smartphone. The Journal of the Acoustical Society of America. Retrieved from https://halshs.archives-ouvertes.fr/halshs-01565214/.

Radicchi, A. (2018). The use of mobile applications in soundscape research: Open questions in standardization. Environment, 5, 7-8.

Seong, J. C., Park, T. H., Ko, J. H., Chang, S. I., Kim, M., Holt, J. B., et al. (2011). Modeling of road traffic noise and estimated human exposure in Fulton County, Georgia, USA. Environment International, 37(8), 13361341.

Son, J. G., Kim, J. T., \& Lee, J. Y. (2008, April 17). Proceedings of the Korean Society for Noise and Vibration Engineering conference: An Analysis of the Status and Problems for the Noise and Vibration Control Laws by Questionnaires. Hoengseong, Gangwon: Hyundai Sungwoo Resort.

Sun, H. S. (2010, May 12). Proceedings of the Korean Society for Noise and Vibration Engineering conference: Study on Efficient Application Plan of Noise Map. Jeju: Jeju Ramada Plaza Hotel.

Sun, H. S. (2011). Establishment on management plan of environmental noise with noise map. Journal of Environmental Impact Assessment, 20(2), 123-131.

Sun, H. S. \& Park, Y. M. (2006, December). Improvement Plan of Aircraft Noise Impact Prediction Technique. Korea Environment Institude. Retrieved from http://webbook.me.go.kr/DLi-File/023/165935.pdf.

Sun, H. S., Park, Y. M., Lee, M. J. (2009a). Environmental Noise Management with Noise Maps. (pp.1-103). Sejong: Korea Environment Institute (KEI).

Sun, H. S., Park, Y. M., \& Lee, M. J. (2009b, October 29). Proceedings of the Korean Society for Noise and Vibration Engineering conference: Present Status of Environmental Noise Impact Assessment and Application Plan of Noise Map. Mokpo, Jeonnam: Mokpo Hyundai Hotel.

Welsh Government. (2013, December). A Noise Action Plan for Wales 20132018. Llywodraeth Cymru Welsh Government. Retrieved from http:// bailey.persona-pi.com/Public-Inquiries/M4\%20-\%20Revised/14.2.12. pdf.

World Health Organization. (2009). Night Noise Guidelines for Europe. Copenhagen: WHO Regional Office Europe. 